ASTHMA

\title{
Association of domestic exposure to volatile organic compounds with asthma in young children
}

\author{
K Rumchev, J Spickett, M Bulsara, M Phillips, S Stick
}

Thorax 2004;59:746-751. doi: 10.1136/thx.2003.013680

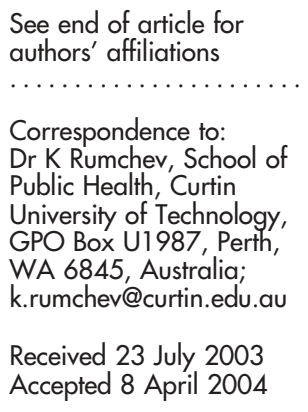

\begin{abstract}
Aim: To investigate the association between domestic exposure to volatile organic compounds (VOCs) and asthma in young children.

Methods: A population based case-control study was conducted in Perth, Western Australia in children aged between 6 months and 3 years. Cases $(n=88)$ were children recruited at Princess Margaret Hospital accident and emergency department and discharged with asthma as the primary diagnosis; 104 controls consisted of children from the same age group without an asthma diagnosis identified through the Health Department of Western Australia. Information regarding the health status of the study children and characteristics of the home was collected using a standardised questionnaire. Exposure to VOCs, average temperature and relative humidity were measured in winter and summer in the living room of each participating household.

Results: Cases were exposed to significantly higher VOC levels $\left(\mu \mathrm{g} / \mathrm{m}^{3}\right)$ than controls $(p<0.01)$. Most of the individual VOCs appeared to be significant risk factors for asthma with the highest odds ratios for benzene followed by ethylbenzene and tolvene. For every 10 unit increase in the concentration of tolvene and benzene $\left(\mu \mathrm{g} / \mathrm{m}^{3}\right)$ the risk of having asthma increased by almost two and three times, respectively. Conclusions: Domestic exposure to VOCs at levels below currently accepted recommendations may increase the risk of childhood asthma. Measurement of total VOCs may underestimate the risks associated with individual compounds.
\end{abstract}

A sthma is the most common chronic disease of childhood in the developed world and its prevalence appears to have increased significantly over the past 30 years..$^{1-3}$ Observations indicate that the rising prevalence has coincided with modifications to the home environment such as the introduction of soft furniture, fitted carpets, air conditioning, and central heating. ${ }^{4}$ In this context, the indoor environment could be of crucial importance since infants spend $80 \%$ of their time indoors at home. ${ }^{5}$ Hence, knowledge regarding the risks for asthma associated with indoor environmental factors will help us to understand how asthma is initiated.

Volatile organic compounds (VOCs) are irritants and indoor sources include solvents, floor adhesive, paint, cleaning products, furnishings, polishes, and room fresheners. ${ }^{6}$ According to Samet, ${ }^{7}$ levels of most VOCs can be 5-10 times higher indoors than outdoors. Indoor exposure to VOCs has been related to asthma and asthmatic symptoms such as nocturnal breathlessness, increased bronchial responsiveness, and decreased lung function. ${ }^{89}$ Ware and colleagues ${ }^{10}$ reported an association between ambient concentrations of VOCs and asthma in children aged 7-13 years of age. Two other experimental studies have shown that VOCs may affect the airways and induce inflammation ${ }^{11}$ and airway obstruction. ${ }^{12}$

The realisation that the early initiation phase of asthma is likely to occur during infancy and that infants spend most of their time indoors provides the rationale for our study of indoor air quality and asthma in young children. ${ }^{13}$ The primary aim of the study was to test the hypothesis that early exposure to VOCs increases the risk of asthma in young children.

\section{METHODS}

\section{Study population}

A population based case-control study was carried out in the Perth metropolitan area, Western Australia, between 1997 and 1999. Children aged between 6 months and 3 years were recruited in order to identify risk factors for asthma that might be important early in life. The study was population based case-control so cases and controls were not matched by age or any other variables. The age group was restricted for cases and controls by defining an eligible age range (6 months-3 years) within which childhood asthma genesis was believed to occur. In order to standardise the diagnosis of asthma and ensure that the "asthma" group was as homogenous as possible, cases $(\mathrm{n}=88)$ were children who attended the accident and emergency department at Princess Margaret Hospital and who were discharged with asthma as the primary diagnosis but not asthma ever. We used the discharge coding to help create a more homogenous group than would be possible from a community sample. Children were reviewed by a paediatric trainee in the emergency department and presumably were diagnosed as asthmatic based upon past history, family history of atopy, presentation, and response to anti-asthma treatment. Children with the final diagnostic coding of bronchiolitis were excluded. Controls $(n=104)$ were children of the same age group as cases, without ever having asthma diagnosed by a doctor, identified through the Health Department of Western Australia. The controls were recruited from the metropolitan community rather than the hospital accident and emergency department because the primary care facility within the accident and emergency department serves the whole metropolitan area and there are no other significant services for the management of acute severe asthma, particularly out of normal business hours.

Written informed consent was obtained from the parents or guardians of all study children. The study protocol was approved by the Princess Margaret Hospital Ethics Committee, Confidentiality of Health Information Committee at the Health Department of Western Australia, and Curtin University Human Research Ethics Committee. 


\section{Health outcomes and house characteristics}

A letter of recruitment was sent to the parent or guardian of each potential participating child. After obtaining informed consent, a modified American Thoracic Society questionnaire (some questions related to ear infections, cystic fibrosis, and pneumonia were omitted) ${ }^{14}$ was administered to parents or guardians of all study subjects who were asked to return the completed form to the research team. The questionnaire included questions regarding potential risk factors for asthma such as personal (age, sex) and susceptibility factors (child's allergy, wheeze, cough, family history of asthma, parental asthma and allergy). Questions related to environmental exposures such as smoking inside (parents and visitors); exposure to gas heating and cooking; presence of kerosene space heaters, wood fire heaters, air conditioning, humidifier; type of floor covering, age of the house, and family pets were also included.

\section{Assessment of indoor exposure}

Indoor exposure measurements of VOCs for cases were performed within 2 weeks of the emergency visit in winter (middle of June to end of September 1998) and then during the opposite season, summer (December 1998 to middle of March 1999). Controls were monitored during the same period of time as the case subjects. VOCs were measured in the living room, $1 \mathrm{~m}$ above the floor, by active sampling using charcoal sorbent tubes. The air sampling rate was $1 \mathrm{l} / \mathrm{min}$ for 8 hours. The charcoal tubes were desorbed with $1 \mathrm{ml}$ carbon disulfide before analysis which was performed with a Perkin Elmer Autosystem XL gas chromatograph equipped with a flame ionisation detector. Ten VOCs associated with respiratory symptoms with common sources found in the home environment such as carpet, furnishing, paints, consumer products ${ }^{6}$ were identified and quantified by comparing their retention times. Total VOCs were defined as the sum of the 10 identified compounds.

The quantity of allergen levels of house dust mite (Der $p$ I) was measured using a monoclonal antibody capture ELISA following the procedure described by Luczynska et al. ${ }^{15}$ Data were analysed using ELISA-AID software and expressed as $\mu \mathrm{g}$ Der $p \mathrm{I} / \mathrm{g}$ fine dust.

The indoor temperature and relative humidity were also measured in the living room using Tinytalk II Data Loggers (Scientific House, Chichester, UK).

\section{Assessment of atopy}

Skin prick tests were performed on all study children using the following common allergens (Miles Inc, Elkhart, IN, USA): cow's milk, egg white, rye grass, grass mix, Dermatophagoides farinae, Dermatophagoides pteronyssinus (house dust mite), cat, dog, Alternaria and Aspergillus. A saline solution was used as a negative control and histamine as a positive control. The largest wheal diameter was determined after 15 minutes. The ratio of allergen wheal size divided by the histamine wheal size was calculated and the tests were considered positive if the ratio was $\geqslant=0.5$. Children with at least one positive skin test were defined as atopic. ${ }^{16}$ The tests were performed between July and September 1998.

\section{Statistical analysis}

Statistical analyses were performed with SPSS for Windows Version 11 and STATA statistical packages. VOC data were log transformed because of the skewed distribution. Simple $\chi^{2}$ square tests and Student's $t$ tests were applied for initial comparisons. Multiple linear regression analysis was used to test the association between VOCs and house characteristics.

A random effect of the logistic regression was used to identify important asthma risk factors. This is a modelling technique for use with dichotomous outcomes in which the responses are correlated. In the present study we have observations on the same individuals at two different time points and a common technique for analysing this type of data is known as generalised estimating equations (GEE), which is like logistic regression but has the capability to take care of multiple observations for the same person by treating the person as a "random effect". Each variable was assessed and was considered significant in the model if the Wald statistic $\mathrm{p}$ value was $<0.05$. All significant variables were entered into a multivariate model as the non-significant factors were systematically removed. Variables considered to be confounding such as age, sex, atopy, socioeconomic status, smoking indoors, presence of air conditioning and house dust mites were kept in the final model. Socioeconomic status was based on area of residence..$^{17}$ Crude and adjusted odds ratios (ORs) for asthma with $10 \mu \mathrm{g} / \mathrm{m}^{3}$ increase of exposure to VOCs were calculated with a 95\% confidence interval (CI). Interaction terms between VOCs and allergen levels of dust mites were also tested in the models. In all statistical analyses two tailed tests were used and a 5\% level of significance was applied.

We calculated that 104 cases and 104 controls would provide $90 \%$ power to detect as significant from $0(\mathrm{p}<0.05)$ a true OR of 2.0 for the association between asthma and exposure to VOCs.

\section{RESULTS}

Eighty percent of those approached agreed to take part in the study (90\% cases and 70\% controls). Results were obtained from 192 children (88 cases and 104 controls). The mean (SD) age of the asthmatic children was 25 (7.46) months and of the controls was 20 (7.54) months. Sixty eight cases (77\%) were defined as atopic compared with 53 controls (51\%). The most common allergy for both asthmatics and non-asthmatics was to house dust mite (D pteronyssinus). Sixty eight asthmatic children $(77 \%)$ had at least one parent with an allergic problem and 57\% had at least one asthmatic parent. More cases than controls reported having wheeze, runny nose, and cough $(\mathrm{p}<0.01$, table 1$)$.

\section{Characteristics of the homes}

The VOCs identified in the homes of participants included benzene, toluene, $m$-xylene, $o, p$-xylene, ethylbenzene, styrene, chlorobenzene, 1,3-dichlorobenzene, 1,2-dichlorobenzene and 1,4-dichlorobenzene, with toluene, xylene, and benzene + toluene being detected in $99 \%$ of the homes studied, xylene in $93 \%$, and benzene in $86 \%$. The highest median concentration was measured for benzene $\left(20.3 \mu \mathrm{g} / \mathrm{m}^{3}\right.$ with a maximum of $81.9 \mu \mathrm{g} / \mathrm{m}^{3}$ ) followed by toluene

\begin{tabular}{|c|c|c|c|}
\hline Variables & Cases & Controls & $\mathrm{p}$ value \\
\hline \multicolumn{4}{|l|}{ Age (months) } \\
\hline $6-12$ & $5(6 \%)$ & $24(23 \%)$ & \\
\hline $13-24$ & $44(50 \%)$ & $53(51 \%)$ & \\
\hline $25-36$ & 39 (44\%) & $27(26 \%)$ & 0.000 \\
\hline \multicolumn{4}{|l|}{ Sex } \\
\hline Boys & 61 (69\%) & $64(62 \%)$ & \\
\hline Girls & $27(31 \%)$ & $40(38 \%)$ & 0.262 \\
\hline Atopy & 68 (77\%) & $53(51 \%)$ & 0.001 \\
\hline Parental asthma & $50(57 \%)$ & $38(36 \%)$ & 0.005 \\
\hline Parental allergy & 68 (77\%) & 74 (71\%) & 0.395 \\
\hline $\begin{array}{l}\text { Family history } \\
\text { of asthma }\end{array}$ & $58(66 \%)$ & $43(41 \%)$ & 0.001 \\
\hline Cough & $86(98 \%)$ & 77 (74\%) & 0.000 \\
\hline Runny nose & 83 (94\%) & 72 (69\%) & 0.000 \\
\hline Wheeze & 85 (97\%) & $45(43 \%)$ & 0.000 \\
\hline
\end{tabular}




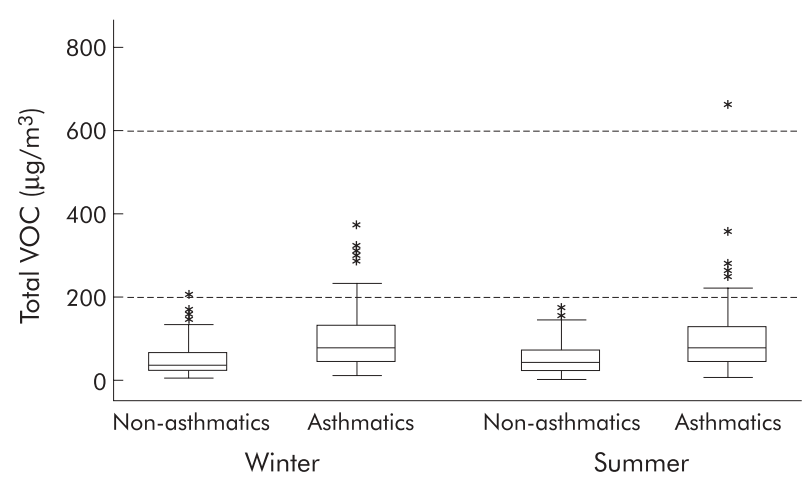

Figure 1 Seasonal differences in exposure levels to total volatile organic compounds (VOCs, $\mu \mathrm{g} / \mathrm{m}^{3}$ ) for asthmatic and non-asthmatic children.

(17.1 $\mu \mathrm{g} / \mathrm{m}^{3}$ (range 0.01-153.9)) and 1,2-dichlorobenzene (16.7 $\mu \mathrm{g} / \mathrm{m}^{3}$ (range 0.01-201.8)). The median concentration of total VOCs was $54.9 \mu \mathrm{g} / \mathrm{m}^{3}$ with a maximum of $622 \mu \mathrm{g} / \mathrm{m}^{3}$ measured in a house in which the walls of the living room had been recently painted. Recent painting in the house was reported for significantly more cases than for children without asthma $(37(22 \%) \vee 28(14 \%), \mathrm{p}<0.05)$. However, significantly more control subjects than cases had air conditioning (54 (52\%) v $29(33 \%), \mathrm{p}=0.008)$.

In a multilinear regression model total VOC levels were significantly $(p=0.045)$ affected by recent painting. Ethylbenzene and xylene levels were significantly increased in association with smoking, the presence of a new carpet and new furniture $(\mathrm{p}<0.05)$. Dust mite allergen levels were also significantly associated with total VOC levels $(p=0.001)$.

\section{Childhood asthma in relation to domestic exposure to VOCs}

Exposure levels to total VOCs were higher during summer than in winter but the differences were not significant (fig l). However, when exposure levels to total VOCs were compared between cases and control subjects, children who had received emergency treatment for asthma were found to have been exposed to significantly higher concentrations of total VOCs than controls $(\mathrm{p}<0.05$, table 2$)$.

Associations between asthma and exposures to VOCs were examined using more powerful multiple logistic regression models (table 3 ).

The ORs were adjusted for the effects of relative humidity and indoor temperature. Other potential confounding factors such as child's age, sex, child's allergy, family history of asthma, socioeconomic status, smoking indoors, season, air conditioning, house dust mites, and gas appliances were also considered in the analysis. Having controlled for these potential confounding variables, children exposed to concentrations of total VOCs of $\geqslant 60 \mu \mathrm{g} / \mathrm{m}^{3}$ (median level of exposure) had a fourfold increased risk of having asthma while children exposed to single compounds such as benzene at levels of $\geqslant 20 \mu \mathrm{g} / \mathrm{m}^{3}$ (median level of exposure) had an eightfold increased risk of asthma (fig 2).

Most of the individual VOCs appeared to be significant risk factors for asthma with the highest ORs for benzene followed by ethylbenzene and toluene (fig 3). For every 10 unit increase in the concentrations of toluene and benzene $(\mu \mathrm{g} /$ $\mathrm{m}^{3}$ ) the risk of having asthma increased by almost two and three times, respectively.

In the final model, interactions between VOCs and allergen levels of dust mites were explored but the only interaction that appeared to be significant was between toluene and house dust mite $(p=0.042)$.

\section{DISCUSSION}

Domestic indoor air levels of volatile organic pollutants are not regulated. However, national organisations such as the National Health and Medical Research Council in Australia ${ }^{18}$ recommend advisory goals in order to protect public healthfor example, $500 \mu \mathrm{g} / \mathrm{m}^{3}$ for total VOCs and $250 \mu \mathrm{g} / \mathrm{m}^{3}$ for any individual compound (one hour average). In the present study the concentrations of total VOCs were low, with a total of two samples exceeding $500 \mu \mathrm{g} / \mathrm{m}^{3}$. The median concentrations of most of the single compounds measured in this study were below $5 \mu \mathrm{g} / \mathrm{m}^{3}$ (except for benzene and toluene), which is consistent with other studies. ${ }^{19}$ It is difficult to compare exposure levels to VOCs between studies when different sampling strategies, sampling techniques, and analyses are applied. According to Wolkoff, ${ }^{20}$ the use of passive sampling may underestimate the levels of exposure to weak sorbents such as benzene. For example, in the indoor air of established dwellings in Germany the median concentration of benzene was $7.8 \mu \mathrm{g} / \mathrm{m}^{3}$ using passive sampling, which was lower than the concentrations of 15 and $16 \mu \mathrm{g} / \mathrm{m}^{3}$ found in US dwellings using active sampling. ${ }^{21}{ }^{22}$ Norbäck et $a l^{8}$ measured the indoor concentrations of VOCs for 2 hours using an active sampling method (similar to the method used in the present study) and found a mean toluene level in dwellings of subjects with attacks of breathlessness of $120 \mu \mathrm{g} / \mathrm{m}^{3}$ (range $1-2330$ ). We do not know whether mean or peak exposure is the important determinant of health effects so, as in other studies, our analysis is a marker of exposure rather than a measure of personal exposure.

We conducted a population based case-control study which is known to have a potential problem with selection bias. The establishment of the case and the control groups could be biased if case and control subjects came from different geographical locations. This bias was minimised by choosing

Table 2 Concentration (range) in $\mu \mathrm{g} / \mathrm{m}^{3}$ and distribution of selected VOCs indoors for cases and controls

\begin{tabular}{|c|c|c|c|c|c|c|c|c|c|}
\hline \multirow{2}{*}{$\begin{array}{l}\text { Volatile organic } \\
\text { compound }\end{array}$} & \multicolumn{4}{|l|}{ Cases } & \multicolumn{5}{|c|}{ Controls } \\
\hline & 25 th & 75th & 90th & Median & 25 th & 75th & 90th & Median & $p$ value \\
\hline Benzene & 17.4 & 34.7 & 46.8 & $24.8(0.01-81.9)$ & 2.01 & 24.1 & 31.7 & $11.8(0.01-58.9)$ & 0.000 \\
\hline Tolvene & 6.3 & 20.6 & 36.9 & $11.9(0.8-153.9)$ & 3.6 & 12.1 & 22.5 & $6.2(0.01-64.8)$ & 0.000 \\
\hline m-Xylene & 0.6 & 3.3 & 15.5 & $1.4(0.01-319.8)$ & 0.01 & 1.5 & 5.2 & $0.7(0.01-31.5)$ & 0.016 \\
\hline o,p-Xylene & 2.8 & 12.3 & 25.1 & $5.9(0.01-93.1)$ & 2.1 & 6.2 & 13.6 & $3.2(0.01-57.4)$ & 0.005 \\
\hline Ethylbenzene & 0.01 & 1.4 & 3.6 & $1.4(0.01-14.7)$ & 0.01 & 1.5 & 3.6 & $0.8(0.01-16.5)$ & 0.425 \\
\hline Styrene & 0.01 & 0.1 & 1.3 & $0.01(0.01-6.4)$ & 0.01 & 0.01 & 0.8 & $0.01(0.01-0.8)$ & 0.230 \\
\hline Chlorobenzene & 0.01 & 0.4 & 46.8 & $0.01(0.01-45.6)$ & 0.01 & 0.01 & 1.4 & $0.01(0.01-21.5)$ & 0.003 \\
\hline 1,2-dichlorobenzene & 3.2 & 19.1 & 53.5 & $9.4(0.01-201.8)$ & 1.7 & 11.9 & 0.8 & $4.3(0.01-34.7)$ & 0.000 \\
\hline 1,3-dichlorobenzene & 0.01 & 12.3 & 31.1 & $3.6(0.01-174.3)$ & 0.01 & 5.0 & 22.3 & $1.1(0.01-53.0)$ & 0.003 \\
\hline 1,4-dichlorobenzene & 0.01 & 1.2 & 6.7 & $0.01(0.01-123.9)$ & 0.01 & 0.01 & 5.0 & $0.01(0.01-34.7)$ & 0.540 \\
\hline Total VOCs & 45.0 & 125.5 & 204.6 & $78.5(10.8-622.7)$ & 19.9 & 69.8 & 101.0 & $36.2(2.5-198.2)$ & 0.000 \\
\hline
\end{tabular}


Table 3 Adjusted and unadjusted odds ratio (OR) for the risk of asthma for each $\mathrm{mg}$ increase in exposure to VOCs

\begin{tabular}{|c|c|c|c|c|}
\hline & OR $\ddagger$ & $95 \% \mathrm{Cl}$ & OR† & $95 \% \mathrm{Cl}$ \\
\hline Age & $1.09^{*}$ & 1.05 to 1.13 & $1.08^{*}$ & 1.03 to 1.14 \\
\hline Sex & 1.42 & 0.78 to 2.60 & 2.17 & 0.98 to 4.78 \\
\hline Smoking & 1.04 & 0.42 to 2.60 & 0.86 & 0.28 to 2.62 \\
\hline Temperature & 1.03 & 1.00 to 1.05 & $1.07^{*}$ & 1.02 to 1.11 \\
\hline Humidity & 1.02 & 1.00 to 1.04 & 1.02 & 0.99 to 1.05 \\
\hline Air conditioning & 0.93 & 0.77 to 1.13 & $0.74^{*}$ & 0.58 to 0.95 \\
\hline Dust mite & $2.12^{*}$ & 1.28 to 3.51 & $2.04^{*}$ & 1.08 to 3.86 \\
\hline Atopy & $2.88^{*}$ & 1.51 to 5.47 & $4.98^{*}$ & 2.10 to 11.83 \\
\hline Family history & $2.77^{*}$ & 1.53 to 5.00 & $3.23^{*}$ & 1.55 to 6.75 \\
\hline SES 2 & 1.34 & 0.41 to 4.30 & 1.48 & 0.72 to 8.26 \\
\hline SES 3 & 1.00 & 0.40 to 2.50 & 2.33 & 0.66 to 8.19 \\
\hline SES 4 & 0.78 & 0.33 to 1.82 & 1.80 & 0.57 to 5.67 \\
\hline SES 5 & 0.66 & 0.22 to 1.98 & 1.38 & 0.34 to 5.63 \\
\hline Gas & 0.86 & 0.44 to 1.70 & 0.91 & 0.39 to 2.13 \\
\hline $\begin{array}{l}\text { Total VOC (with } 1 \mu \mathrm{g} / \mathrm{m}^{3} \\
\text { increase in VOC exposure) }\end{array}$ & $1.02^{*}$ & 1.01 to 1.02 & $1.02^{*}$ & 1.02 to 1.03 \\
\hline $\begin{array}{l}\text { Total VOC (with } 10 \mu \mathrm{g} / \mathrm{m}^{3} \\
\text { increase in VOC exposure) }\end{array}$ & $1.2^{*}$ & 1.13 to 1.27 & $1.27^{*}$ & 1.18 to 1.37 \\
\hline $\begin{array}{l}\text { SES }=\text { socioeconomic status; } \\
{ }^{*} p<0.05 \text {. } \\
\text { †Adjusted odds ratio. } \\
\text { ¥Unadjusted odds ratio. }\end{array}$ & $C=v$ & anic compoun & & \\
\hline
\end{tabular}

cases and controls from the same population within the Perth metropolitan area and there was no difference between the study groups with regard to socioeconomic status.

Misclassification of controls is also acknowledged in the present study. This is a common potential problem in studies of asthma in children of this age group as they often have the disease without having received a diagnosis. Based on the findings of Yuan et al, ${ }^{23}$ we assumed that the annual incidence of asthma in infants is approximately $5 \%$ so the number of infants (6-12 months) in the control group who might develop asthma in the 3 years following the study is three. Since we did not find a significant change in the model after we added the number of controls with the lowest exposure to total VOCs to the case group, we do not believe that this is a major source of concern.

Since the present study examined the risk factors for asthma, it is possible that families with a knowledge or risk of asthma were more likely to agree to participate. The most important risk factor for asthma is atopy. However, the proportion of children with atopy and the proportion of children with an atopic parent in the control group was similar to those previously reported in Perth. ${ }^{24}$

There is a potential problem with the validity of the diagnosis of asthma in the present study because of the young age of the study children and the difficulty in differentiating wheezing illnesses in this age group. However,

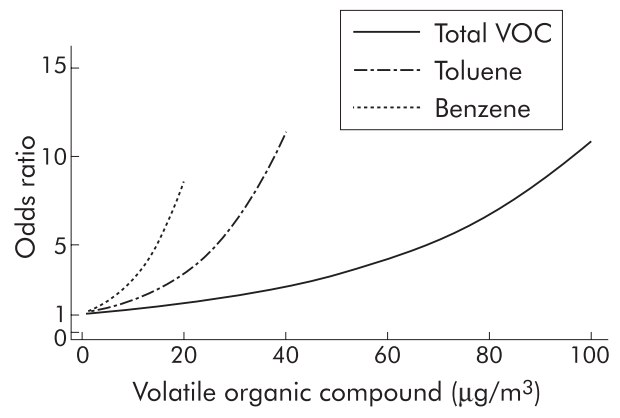

Figure 2 Asthma in young children associated with exposure to indoor volatile organic compounds $\left(\mu \mathrm{g} / \mathrm{m}^{3}\right)$ : odds ratios adjusted for age, sex, atopy, socioeconomic status, smoking indoors, air conditioning, house dust mites, and gas appliances. the setting for the diagnosis was a children's teaching hospital and therefore the cases were more likely to form a homogenous group than children of a similar age recruited from a number of primary care facilities.

Questionnaire responses were also subject to recall or observational biases. Even with the use of a standardised questionnaire, parents may apply different interpretations of questions in relation to their children's symptoms.

Potential problems arising from multicolinearity are recognised, resulting from the inevitable correlation between different VOCs. These could be avoided if the total VOCs were included in the final model, but this would assume equal toxicity per unit concentration for each compound. To avoid having to make this assumption we chose to treat each VOC independently, but this may make some of the risk estimates (ORs) for specific VOCs inaccurate. Since this is most likely to have occurred for those VOCs with lower risk estimates, we do not believe that this is a major source of concern.

To estimate the independent effect of VOCs on asthma we fitted a model including all significant VOCs as independent factors. This showed that only benzene, toluene and dichlorobenzene appeared to have a significant independent

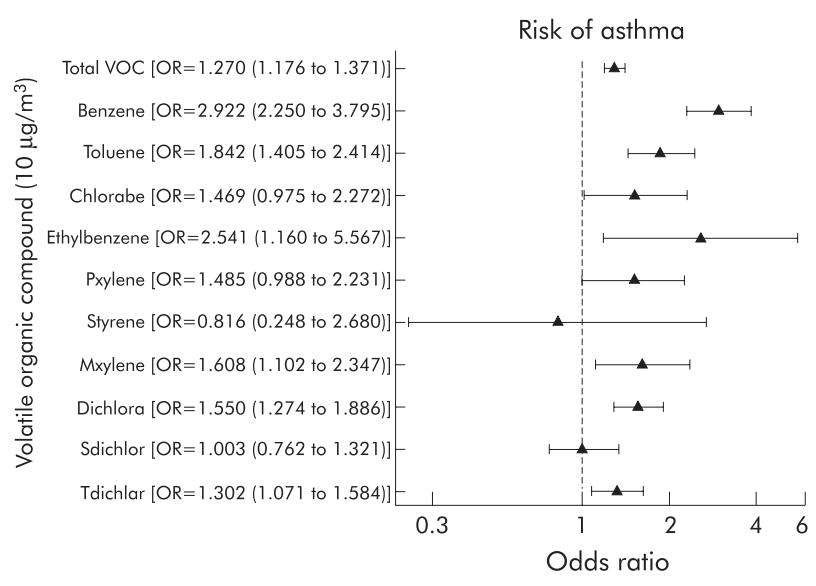

Figure 3 Adjusted odds ratio with $\pm 95 \%$ confidence intervals for the risk of asthma with each $10 \mathrm{mg}$ increase in exposure to VOCs. 
effect on asthma (after adjusting for all covariates and each VOC) with ORs of 1.09 (95\% CI 1.06 to 1.12 ), 1.03 (95\% CI 1.02 to 1.07 ), and 1.02 (95\% CI 1.02 to 1.04 ), respectively. The rest of the compounds were either marginally significant or not significant at all. These results were similar to our original results where each VOC was assessed in isolation (benzene: OR 1.11 (95\% CI 1.08 to 1.14); toluene: OR 1.06 (95\% CI 1.04 to 1.09 ), and dichlorobenzene: OR 1.04 (95\% CI 1.02 to 1.06). Both models were adjusted for age, sex, smoking status, temperature, humidity, air conditioning, house dust mites, atopy, family history of asthma, socioeconomic status, and presence of gas appliances.

Wolkoff et $a l^{25}$ have recently proposed that products of reactions between VOCs and other air pollutants may produce irritant substances that are more important for adverse health effects than direct exposure to the VOCs. Following this theory, we explored the interaction between VOCs and allergen levels of house dust mites and found a significant interaction only with toluene. Norbäck et $a l^{8}$ found a significant relation between presence of house dust mites and the concentration of total VOCs and some subclasses of VOCs.

Reverse causation was also considered in this study. Due to limited data on concentration distribution of VOCs in residential environments in relation to the use of consumer products such as cleaners, paints, and hobby supplies, the study hypotheses were based on the knowledge that VOC levels were significantly influenced by the ambient VOCs, so no hygiene hypotheses were tested. However, a recent study reported that home environmental lifestyle factors including cleaning frequency do not affect the indoor exposure to endotoxins. ${ }^{26}$

The present study established a significant association between VOCs and recent painting, new carpets, new furniture, and smoking indoors which is consistent with the findings of other studies. ${ }^{6} 89$ In a recent study ${ }^{13}$ we showed that exposure to formaldehyde levels of $\geqslant 60 \mu \mathrm{g} / \mathrm{m}^{3}$ increased the risk of asthma in young children. Thus, in order to examine whether the presence of formaldehyde confounds the effect of total VOCs on asthma, we fitted a model including formaldehyde. The results showed that exposure to total VOCs still had a highly significant effect on asthma. The model was also adjusted for air conditioning, house dust mites, atopy, family history of asthma, socioeconomic status and the presence of gas appliances.

Assumptions for sample size calculations in our study were based on an OR of 2.0 which applies to dichotomous risk factors. However, due to time and other resources constraints, an OR of 2.5 was chosen which corresponds to a smaller sample size of 208 study subjects ( 104 cases and 104 controls) and therefore resulted in a study with a lower statistical power. It is acknowledged that the selection of a smaller sample size is a limitation of the study and will have increased the probability of a type II error for non-significant risk factors.

Despite the potential limitations, the results of this study suggest that exposure to VOCs in residential settings is associated with an increased risk of asthma in young children. Children exposed to total VOCs at levels of $\geqslant 60 \mu \mathrm{g} / \mathrm{m}^{3}$ are four times more likely to have asthma than those who were not exposed to such levels, while children exposed to a single compound such as benzene at levels of $\geqslant 20 \mu \mathrm{g} / \mathrm{m}^{3}$ were eight times more likely to have asthma. This case-control study therefore supports the hypothesis that exposure to indoor environmental factors contributes to the increased risk of asthma. ${ }^{27}$

In this study we were concerned with the effect of exposure to VOC on the early expression of asthma. Our results cannot therefore be generalised except that, since we studied young children with asthma, our findings support the hypothesis that exposure to indoor pollutants might be important in the genesis of asthma. Panel studies are required to examine further the relationships between indoor exposures and asthma symptoms in older asthmatics similar to those used to study the effects of ambient pollution.

Given that some VOCs are carcinogenic and some may be significantly related to asthma, it is important that an increased understanding of the factors that affect their indoor concentration is achieved. At present there is insufficient evidence concerning the health implications of VOCs at concentrations commonly found inside houses. Research in this area is complicated by the wide range of relevant VOCs and the continual appearance of new products which release different combinations of these compounds.

\section{Authors' affiliations}

K Rumchev, J Spickett, M Phillips, School of Public Health, Curtin University of Technology, Perth, WA 6845, Australia

M Bulsara, University of WA, School of Population Health, Faculty of Medicine and Dentistry, Crawley, WA 6009, Australia

S Stick, Princess Margaret Hospital for Children, Department of Respiratory Medicine, GPO Box D184, Perth, WA 6001, Australia

\section{REFERENCES}

1 Anderson H, Butland B, Strachan D. Trends in prevalence and severity of childhood asthma. BMJ 1994;308:1600-4.

2 Burney P, Chinn S, Rona R. Has the prevalence of asthma increased in children? Evidence from the national study of health and growth 1973-86. BMJ 1990;300:1306-10.

3 Peat J, van den Berg R, Green W, et al. Changing prevalence of asthma in Australian children. BMJ 1994;308:1591-6.

4 Hyndman S, Brown D, Ewan P, et al. Humidity regulation in the management of asthma patients sensitized to house dust mites. Q J Med 1994;87:367-72.

5 Holt $\mathbf{P}$, Macaubas $C$, Stumbles $P$, et al. The role of allergy in the development of asthma. Nature 1999;402(Suppl 6760):B12-7.

6 Maroni M, Seifert B, Lindvall T. Indoor air quality: a comprehensive reference book. Amsterdam: Elsevier Science, 1995.

7 Samet J. Environmental controls and lung disease. Am Rev Respir Dis 1990;142:915-39.

8 Norbäck D, Björnsson E, Janson C, et al. Asthmatic symptoms and volatile organic compounds, formaldehyde, and carbon dioxide in dwellings. Occup Environ Med 1995;52:388-95

9 Weislander G, Norbäck D, Bïörnsson E, et al. Asthma and the indoor environment: the significance of emission of formaldehyde and volatile organic compounds from newly painted indoor surfaces. Int Arch Occup Environ Health 1997;69:1 15-24.

10 Ware J. Respiratory and irritant health effects of ambient volatile organic compounds. The Kanawha County Health Study. Am J Epidemiol 1993;137:1287-301.

11 Koren H, Graham D, Devlin R. Exposure of humans to volatile organic mixture. III. Inflammatory response. Arch Environ Health 1992;47:39-44.

12 Harving $H$, Dahl R, Molhave L. Lung function and bronchial reactivity during exposure to volatile organic compounds. Am Rev Respir Dis $1991 ; 143: 751-4$

13 Rumchev K, Spickett J, Bulsara M, et al. Domestic exposure to formaldehyde significantly increases the risk of asthma in young children. Eur Respir J 2002;20:403-8.

14 Ferris B. Epidemiology standardization project (ATS). Am Rev Respir Dis 1978;1 18:1-120.

15 Luczynska CM, Arruda LK, Platts-Mills TA, et al. A two site monoclonal antibody ELISA for the quantification of the major Dermatophagoides allergens Der $\mathrm{p} 1$ and Der f 1. J Immunol Methods 1989;1 18:227-35.

16 Meinert R, Frisher T, Karamaus W, et al. Influence of skin prick test criteria on estimation of prevalence and incidence of allergic sensitization in children. Allergy 1994:49:526-32.

17 Australian Bureau of Statistics. Socioeconomic indexes for areas. ABS Catalogue N 2039.0. Commonwealth of Australia, 1998.

18 National Health and Medical Research Council (NHMRC). Interim national indoor air quality goals, The 115th NHMRC Session. Australian Department of Health and Aged Care, 1995.

19 Brown S, Sim M, Abramson M, et al. Concentrations of volatile organic compounds in indoor air-a review. Indoor Air 1994;4:123-34.

20 Wolkoff P. Volatile organic compounds: sources, measurements, emissions, and the impact on indoor air quality. Indoor Air 1995;3:26-35.

21 Wallace LA. Personal exposure, indoor and outdoor air concentrations, and exhaled breath concentrations of selected volatile organic compounds measured for 600 residents of New Jersey, North Dakota, Carolina and North California. Toxicol Environ Chem 1986;12:215-36.

22 Wallace LA. The exposure of the general population to benzene. Cell Biol Toxicol 1989;5:297-314. 
23 Yuan WK, Fonager K, Olsen J, et al. Prenatal factors and use of anti-asthma medications in early childhood: a population-based Danish birth cohort study. Eur $J$ Epidemiol 2003;18:763-8.

24 Oddy W, Klerk N, Sly $\mathrm{P}$, et al. The effects of respiratory infections, atopy, and breastfeeding on childhood asthma. Eur Respir $J$ 2002; 19:899-905.
25 Wolkoff $\mathrm{P}$, Clausen PA, Jensen $\mathrm{B}$, et al. Are we measuring the relevant indoor pollutants? Indoor Air 1997;7:92-106.

26 Gereda JE, Klinnert MD, Price MR, et al. Metropolitan home living conditions associated with indoor endotoxin levels. J Allergy Clin Immunol 2001;107:790-6.

27 Karol MH. Respiratory allergy: what are the uncertainties? Toxicology 2002;181-182:305-10.

\section{LUNG ALERT}

\section{Inhaled corticosteroids may decrease the severity of chronic cough}

$\Delta$ Chaudhuri R, McMahon AD, Thomson $\sqcup$, et al. Effect of inhaled corticosteroids on symptom severity and sputum mediator levels in chronic persistent cough. J Allergy Clin Immunol 2004;113:1063-70.

r

his double blind, randomised, placebo controlled, crossover study was performed in 88

patients who had chronic cough for more than 1 year. Patients were treated with

inhaled fluticasone $500 \mu \mathrm{g}$ or matching placebo twice daily for 14 days with a 2 week washout phase in between. There was a statistically significant decrease in the cough visual analogue scale (VAS) between the fluticasone and placebo groups (difference in differences $=1 ; 95 \%$ CI 0.4 to $1.5, \mathrm{p}<0.001)$. The mean percentage change in cough VAS in the fluticasone group was $22.3 \%$. Inflammatory mediators were measured at baseline and after treatment. Some inflammatory mediators decreased with inhaled fluticasone (eosinophilic cationic protein, exhaled nitric oxide, and carbon monoxide) while others were unchanged.

This study shows that inhaled steroids can be used empirically to treat chronic cough present for more than 1 year, resulting in a modest clinical improvement. As expected, mediators related to eosinophilic inflammation predict corticosteroid responsiveness. This study suggests that drugs designed to target other inflammatory mediators might also be beneficial.

T D Yan

Cleveland Clinic Foundation, Cleveland, USA; yant@ccf.org 